\title{
Color removal from textile wastewater using date seed activated carbon
}

\author{
M. A. Rahman1, T. Ahmed ${ }^{2 *}$, I. N. Salehin², M. D. Hossain ${ }^{2}$ \\ ${ }^{1}$ ITN-BUET: International Training Network Centre for Water Supply and Waste Management, Bangladesh University of \\ Engineering and Technology, Dhaka- 1000, Bangladesh \\ ${ }^{2}$ Department of Civil Engineering, Bangladesh University of Engineering and Technology, Dhaka- 1000, Bangladesh
}

\begin{abstract}
Powdered Activated Carbon (PAC) developed from date seeds was used as an adsorbent for the removal of color from textile wastewater. Batch adsorption experiments were performed in the laboratory with varying process parameters (temperature, $\mathrm{pH}$, agitation, adsorbent dosage, particle size) over a range of contact periods and wastewater pollutant (color) levels. It was found that the removal mechanism could be better characterized by the Freundlich adsorption isotherm model compared to the Langmuir model. Also, The Lagergren's pseudo second order kinetic model fitted relatively well $\left(R^{2}=0.99\right)$ over the selected range of contact times $(5-60$ minutes $)$ and initial color concentrations (800-1200 Pt-Co unit) compared to the pseudo-first order model indicating that chemisorption may be playing a dominant role in the adsorption process. Both external film and intra-particle pore diffusion mechanism were involved in the adsorption process but film diffusion was found to be rate limiting. While analyzing the thermodynamics, the negative value of free energy ( -1.83 to $-3.4 \mathrm{KJ} / \mathrm{mole})$, positive value of enthalpy $(0.26$ to $0.28 \mathrm{KJ} / \mathrm{mole})$ and entropy $(0.97$ to $1.01 \mathrm{~J} / \mathrm{K} / \mathrm{Mole})$ associated with the color removal mechanism indicated that adsorption was spontaneous and endothermic with increased disorder and randomness at the solid-liquid interface of the date seeds PAC. These experiments suggests that date seeds PAC is a very effective adsorbent, capable of removing a significant amount of color from industrial wastewater if process variables can be optimized and can be explored as a potential low-cost alternative to expensive tertiary treatment options.
\end{abstract}

Keyword: Date seeds; textile wastewater; adsorption isotherm; activated carbon; adsorption kinetics

\section{Introduction}

Colored wastewater generated from textile dyeing industries is a significant cause of concern in developing countries owing to its potential to escalate environmental pollution (Khehra et al., 2005). Many complicated processes in textile manufacturing such as washing, dyeing, printing, finishing etc. use an assortment of dyes, which are responsible for producing colored wastewater (Quader, 2010). Color or dyes have recalcitrant and non-biodegradable characteristics and generally cannot be removed efficiently through conventional treatment processes. If released in the environment, they tend to persist over long distances in flowing water, can affect sunlight penetration through the water column, can retard photosynthesis and reduce the availability of dissolved oxygen in water (Khehra et al., 2005). Composite textile effluent is characterized by significantly high Biochemical Oxygen Demand (BOD), Chemical Oxygen Demand (COD) and Total Dissolved Solids (TDS) content along with a large number of nonbiodegradable organic dyes and other chemicals used in manufacturing (Quader, 2010). Inefficiencies in dyeing can also result in large amounts of the dyestuff being directly lost to the wastewater during textile processing, which ultimately finds its way into the environment (Quader, 2010).

Different methods of color removal from industrial effluents have been proposed which include aerobic and anaerobic microbial degradation, coagulation, flotation, membrane filtration and chemical oxidation but none of these methods have been found to be effective enough for the industrialists to adopt for the treatment of colored effluents (Churchley, 1994). For example, biological treatment processes remove BOD, COD and suspended solids to some extent, but they have been found to be largely ineffective in removing color from wastewater (Churchley, 1994). Also, coagulation process effectively decolorizes insoluble dyes but fails to work well with soluble ones (Churchley, 1994). Adsorption, on the other hand, has been found to be very efficient in treating wastewater containing chemically stable pollutants,

*Corresponding author: e-mail: tanvirahmed@ce.buet.ac.bd 
is a sludge free process and can completely remove even very minute amounts of dyes from wastewater (Guendy, 2006; El-Nemr et al., 2009; Nigarn et al., 1996). Activated carbon is the most effective adsorbent that is typically employed to treat wastewater containing different classes of dyes as well as organic matter (Kadirvel et al., 2003). It contains extended surface area, large proportion of internal voids, high adsorption capacity and a high degree of surface activity (Malik, 2003). Commercially available activated carbon are expensive and its use can be cost-prohibitive for large-scale wastewater treatment (Habib et al., 2006). In developing countries, they may not be easily available and may not be effective in comparison with cost and adsorption capacity (Pollard et al., 1992 and Namasivayam, 1995). There could be other regulatory issues deterring efficient removal of color from industrial wastewater in developing countries. For example, in Bangladesh the industrialists are reluctant to invest in additional treatment processes to remove color after applying conventional treatment to reduce BOD, COD, TSS and TDS particularly when the discharge standard for textile effluent does not specify color of effluent as a parameter to be regulated (ECR, 1997). An affordable solution to color removal can encourage these industrialists to adopt such methods and reduce the environmental burden of their effluent wastewater.

In search of low-cost adsorbents, some researchers investigated the adsorption characteristics of locally available materials like rice husk (Rahman et al., 2013), sawdust, mango seed (Abdus-Salam et al., 2014), mucunapruriens seed shells (Igwegbe et al., 2016), pea shells (Pisum sativum) (Geçgel et al., 2013), and water hyacinth (Karim et al., 2006). Here we explore the efficiency of Powdered Activated Carbon (PAC) derived from date seeds, an abundantly available organic waste in Bangladesh, as an adsorbent for the removal of color from textile effluents. The performance of date seeds PAC as an adsorbent has previously been studied using synthetic wastewater prepared from stock solutions of dyes such as maxilon blue, methylene blue and methyl orange (Alqaragully, 2014; Islam et al., 2015; Reddy et al., 2012). However, for practical purpose (such as designing of tertiary treatment units) it is important to assess the effectiveness of the method with factory-generated effluent. Here we assess the capacity of date seeds PAC to remove color from the effluent wastewater of a typical textile washing plant in Bangladesh. First, we determined the effect of different physical factors on the adsorption capacity of date seeds. Then we characterized the adsorption process using isotherms; the kinetics and thermodynamics of adsorption were also explored. The objective of the study is to establish date seeds PAC as an affordable alternative to other expensive tertiary treatment methods.

\section{Materials and methods}

The activated carbon was prepared from date seeds in laboratory. Activation agent $\mathrm{ZnCl}_{2}$ was procured from $\mathrm{HACH}$. Wastewater sample was collected from the equalization tank of Echotex Limited, an export oriented composite textile industry in Bangladesh located at the district of Gazipur. The wastewater was filtered using $0.45 \mu \mathrm{m}$ nylon filter paper (Whatman nylon membrane filters, WHA7404004)

\section{Preparation of adsorbent}

Date seeds, collected from Rajshahi and Jessore districts of Bangladesh, were washed several times and dried under sunlight until completely dry. The dried seeds were fragmented into small pieces by a cutter and were packed in a crucible in a moderately dense manner. The seeds were carbonized in a Muffle Furnace (Gerhardt) at $500{ }^{\circ} \mathrm{C}$ for 1 hour and then pulverized to powder form in a domestic grinder. The carbonized date seeds powder was activated by soaking overnight in $1 \mathrm{M} \mathrm{ZnCl}_{2}$ solution. A mass ratio of 1:1 is maintained between date seeds powder and $\mathrm{ZnCl}_{2}$ (i.e. $100 \mathrm{gm}$ date seeds powder was immersed in $743 \mathrm{ml}$ of $1 \mathrm{M}$ $\mathrm{ZnCl}_{2}$ solution). After overnight soaking, the date seeds powder was filtered, washed several times and dried in an oven at $100^{\circ} \mathrm{C}$ for 4 hours and it was ready for use in experiments.

\section{Methods of analysis}

The color concentration was measured (in Pt-Co unit) using a Spectrophotometer $(\mathrm{HACH}, \mathrm{DR} / 4000 \mathrm{U})$, and the $\mathrm{pH}$ was measured using $\mathrm{pH}$ meter (HACH, HQ11d). Activated carbon was weighed using electronic balance, temperature was recorded using thermometer and date seeds particle size was graded into three size fractions $(<150 \mu \mathrm{m}, 150-300$ $\mu \mathrm{m}$ and $300-425 \mu \mathrm{m}$ ) using US standard sieves (ASTM E11).

\section{Batch adsorption experiments}

Adsorption of color on date seeds PAC was carried out through batch experiments. For batch adsorption studies, a series of $250 \mathrm{~mL}$ conical flasks, each filled with $100 \mathrm{~mL}$ wastewater of varying color concentrations adjusted to desired $\mathrm{pH}$ levels ( $\mathrm{pH} 8$ ), were employed. $0.5 \mathrm{~g}$ adsorbent (activated carbon) was added to each flask, placed in a rotating shaker (GFL, D-30938, Burgwedel / Germany) and agitated intermittently for different time periods $(5,10,15$, 20, 30 and 60 minutes). After the desired time period, the respective conical flask was taken out from the shaker, and 
the fresh supernatant was extracted by pipette. The supernatant was filtered using $0.45 \mu \mathrm{m}$ nylon filter paper and residual color concentration of the filtrate was measured. Equilibrium contact time was chosen based on the contact period after which no significant adsorption takes place. Batch adsorption experiments were carried out for different quantities of adsorbent $(0.4,0.6,0.8,1.0,1.2$ and $1.4 \mathrm{~g})$ to find out the optimum dose at equilibrium contact time. Using predetermined equilibrium contact time and optimum dosage, batch adsorption studies were carried out at different temperatures $\left(30 \pm 1^{\circ} \mathrm{C}, 35 \pm 1^{\circ} \mathrm{C}\right.$ and $\left.45 \pm 1^{\circ} \mathrm{C}\right)$, agitation speeds (150, 200 and $250 \mathrm{rpm}), \mathrm{pH}$ (from 5 to 11) and with different particle sizes $(<150 \mu \mathrm{m}, 150-300 \mu \mathrm{m}$ and $300-425 \mu \mathrm{m})$ for the samples with initial color concentrations of 800, 1000 and 1200 Pt-Co.

\section{Results and discussion}

Effect of contact time and adsorbent dosage on color removal

Effect of contact time with initial color concentration ranging from 800 to $1200 \mathrm{Pt}-\mathrm{Co}$ on removal of color of textile wastewater using date seeds PAC is presented in Fig. 1(a). The adsorption of color was rapid in first 5 minutes for all three initial concentrations $(800,1000$ and $1200 \mathrm{Pt}$ Co) and after 30 minutes, the incremental amount of color adsorbed was insignificant with the increase of contact time. Therefore, for further experiments 30 minutes was considered as the equilibrium contact time with these wastewater samples. At equilibrium contact time, a 75\% color removal was obtained for both the samples having initial color concentration of 800 and $1000 \mathrm{Pt}-\mathrm{Co}$ and $70 \%$ color removal was achieved for the wastewater having 1200 Pt-Co initial concentration. At the start of experiment, the available sites present in adsorbent are more, so the adsorption rate is high. As the time progresses the availability of active sites inside or outside of adsorbent gradually decreases, so the color removal gradually decreases and after the equilibrium time, the adsorption rate was not significant. Adsorption rate typically increases with the increase in initial color concentration as increased color concentration increases the mass transfer driving force and hence the rate at which color induced molecules pass from the bulk solution to the particle surface. For $800 \mathrm{Pt}-\mathrm{Co}$ initial color concentrations, color adsorption rate was 120 Pt-Co per gram of adsorbent per litre; whereas adsorption rate was $150 \mathrm{Pt}-\mathrm{Co}$ per gram of adsorbent per litre for 1000 $\mathrm{Pt}-\mathrm{Co}$ initial concentration and $168 \mathrm{Pt}-\mathrm{Co}$ per gram of adsorbent per litre for $1200 \mathrm{Pt}-\mathrm{Co}$ color concentration.

Increasing the dosage of date seeds PAC increases the availability of surface active sites for adsorption and results in higher color removal. Fig. 1(b) shows that the amount of color removal increased from 77 to 96 percent with increase in dosage of adsorbent from 4 to $14 \mathrm{~g} / \mathrm{L}$ for $1200 \mathrm{Pt}-\mathrm{Co}$ initial color concentration. These results are quite comparable to that using commercially available PAC as it was previously found that a COD removal of 88 to 98 percent could be obtained for low and medium strength textile wastewater with a PAC dose of $15 \mathrm{~g} / \mathrm{L}$ (Yeh et al., 2002). The adsorbent dosage corresponding to $87 \%$ color removal (i.e. $7 \mathrm{~g} / \mathrm{L}$ ) has been used as a reference dose in subsequent experiments.

\section{Effect of temperature on color removal}

Thermodynamic parameters such as heat of adsorption and energy of activation play an important role in modulating adsorption behavior and both the parameters are strongly dependent on temperature (Al-Ghouti et al., 2005).

Adsorption of color at three different temperatures $\left(30^{\circ} \mathrm{C}\right.$, $35^{\circ} \mathrm{C}$ and $45^{\circ} \mathrm{C}$ ) onto date seeds PAC was studied for 800 , 1000 and $1200 \mathrm{Pt}-\mathrm{Co}$ initial color concentrations (Fig. 1(c)). It is observed that with the increase in temperature color removal percentage increased. Color removal increased from 67.5 to $75 \%, 69$ to $76 \%$ and 72 to $78.33 \%$ with increase in temperature from $30^{\circ} \mathrm{C}$ to $45^{\circ} \mathrm{C}$ for samples having initial color concentration of 1200,1000 and $800 \mathrm{Pt}-\mathrm{Co}$ respectively. The increase in color removal percentage with the increasing experimental temperature may be attributed to the fact that as the temperature increases, rate of diffusion of adsorbate molecules across the external boundary layer and the internal pores of date seeds PAC also increases.

\section{Effect of agitation speed on color removal}

The adsorption of color by date seeds PAC for different agitation speeds of shaker ranging from 150 to $250 \mathrm{rpm}$ with varying initial concentration from 800 to $1200 \mathrm{Pt}-\mathrm{Co}$ were studied. The amount adsorbed was found to increase from 120 to $130 \mathrm{Pt}-\mathrm{Co}$ per gram of adsorbent per litre with increase in agitation speed of shaker from 150 to $250 \mathrm{rpm}$ for a sample of $1200 \mathrm{Pt}-\mathrm{Co}$ initial color concentration. The color removal percentage increased with the increase of agitation speed of the shaker as shown in Fig. 1(d). This may be due to the fact that with low agitation speed of shaker, greater contact time is required to attain the equilibrium. With the increase of initial color concentration, the \% color removal was generally found to decrease (Fig. 1(d)). Color removal increased from 65 to $71.25 \%, 68$ to $74 \%$ and 70 to $76 \%$ with increase in agitation speed of shaker from $150 \mathrm{rpm}$ to $250 \mathrm{rpm}$ for samples having initial color concentration of 1200, 1000 and $800 \mathrm{Pt}-\mathrm{Co}$ respectively. 
(a)

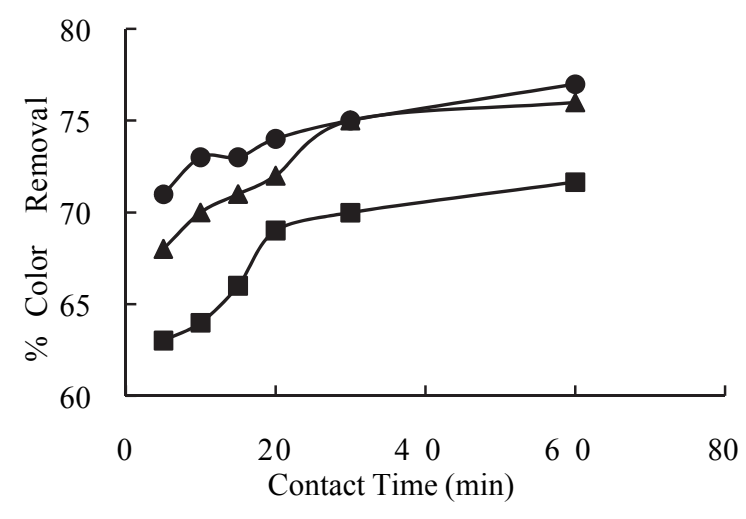

(c)

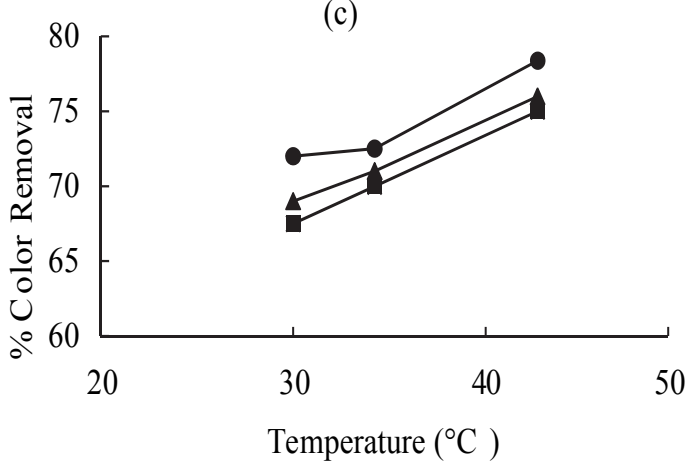

(e)

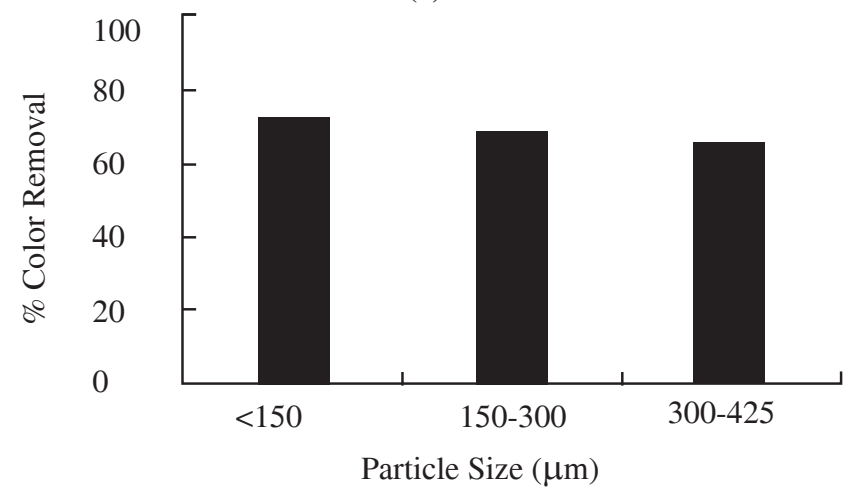

(b)

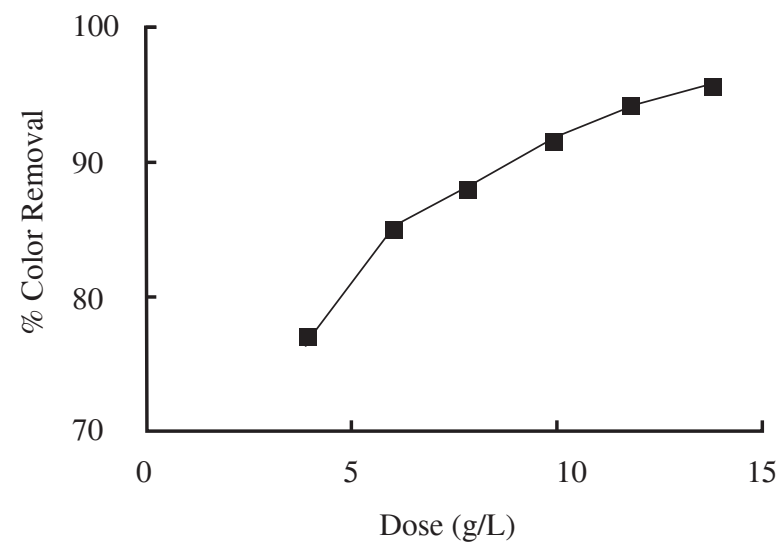

(d)

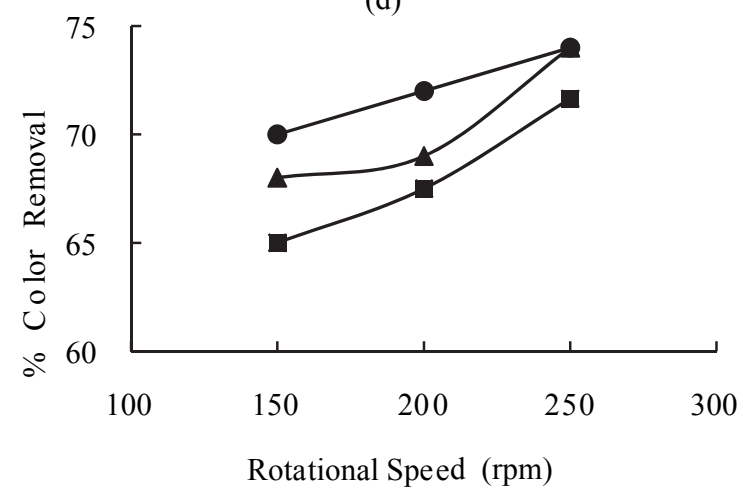

(f)

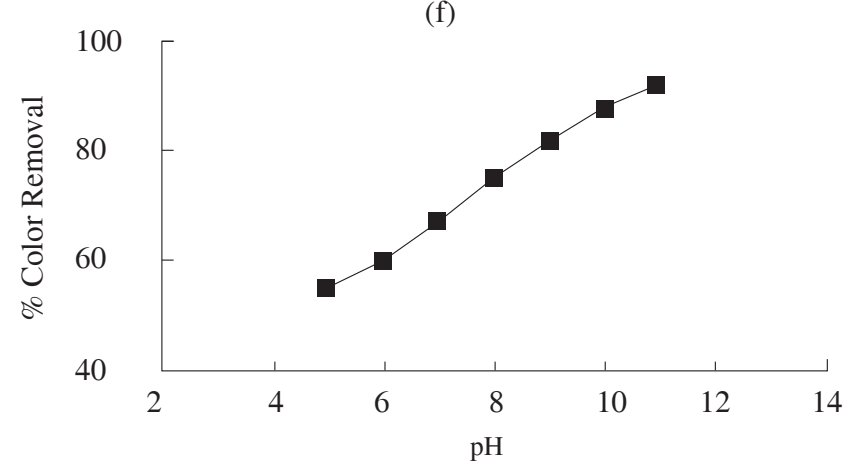

Fig. 1. Effects of (a) contact time (Dosage: $5 \mathrm{~g} / \mathrm{l}$, agitation speed: $200 \mathrm{rpm}$, temperature: $30^{\circ} \mathrm{C}, \mathrm{pH}: 8.0$, particle size: $150-300 \mu \mathrm{m}$ ), (b) absorbent dosage (Contact time: $30 \mathrm{~min}$, agitation speed: $200 \mathrm{rpm}$, temperature: $30^{\circ} \mathrm{C}, \mathrm{pH}: 8.0$, particle size: $150-300$ $\mu \mathrm{m}$ ), (c) temperature (Dosage: $7 \mathrm{~g} / \mathrm{l}$, agitation speed: $200 \mathrm{rpm}$, Contact time: $30 \mathrm{~min}, \mathrm{pH}:$ 8.0, particle size: 150-300 $\mu \mathrm{m}$ ) (d) agitation speed (Contact time: $30 \mathrm{~min}$, Dosage: $7 \mathrm{~g} / \mathrm{l}$, temperature: $30^{\circ} \mathrm{C}, \mathrm{pH}$ : 8.0, particle size: $\left.150-300 \mu \mathrm{m}\right),(\mathrm{e})$ particle size (Initial concentration: $1200 \mathrm{Pt}-\mathrm{Co}$, Contact time: $30 \mathrm{~min}$, Dosage: $7 \mathrm{~g} /$, temperature: $30^{\circ} \mathrm{C}$, $\mathrm{pH}$ : 8.0, agitation speed: $200 \mathrm{rpm}$ ), (f) pH (Initial concentration: $1200 \mathrm{Pt}-\mathrm{Co}$, contact time: $30 \mathrm{~min}$, dosage: $7 \mathrm{~g} / \mathrm{l}$, temperature: $30^{\circ} \mathrm{C}$, particle

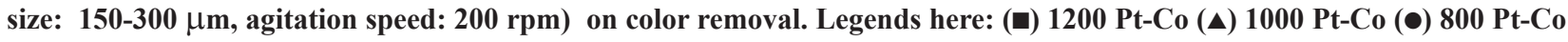
unit of initial color concentration.

\section{Effect of particle size on color removal}

Batch adsorption experiments was carried out for wastewater having initial color concentration of $1200 \mathrm{Pt}-\mathrm{Co}$ using date seeds PAC for three different particle sizes: $<150$ $\mu \mathrm{m},(150-300) \mu \mathrm{m}$ and (300-425) $\mu \mathrm{m}$. Color removal efficiency was found to decrease with increased particle size. About $72 \%, 68 \%$ and $65 \%$ color was removed using 
adsorbent particle size $<150 \mu \mathrm{m}, 150-300 \mu \mathrm{m}$ and 300-425 $\mu \mathrm{m}$ respectively (Fig. 1(e)). This may be due to the fact that smaller particle sizes offer large surface area and hence large number of active sites for adsorption to take place.

\section{Effect of pH on color removal}

Effect of $\mathrm{pH}$ on removal of color using date seeds PAC was investigated over a range of $\mathrm{pH}$ from 5 to 11 . Batch adsorption experiment was carried out with the sample of initial color concentration $1200 \mathrm{Pt}-\mathrm{Co}$ (contact time: $30 \mathrm{~min}$, dosage: $7 \mathrm{~g} / \mathrm{l}$, temperature: $30^{\circ} \mathrm{C}$, particle size: $150-300$ $\mu \mathrm{m}$, agitation speed: $200 \mathrm{rpm}$ ). The removal percentage of color increased with increase of $\mathrm{pH}$ from 5 to 11 . Maximum color removal (92\%) was observed at $\mathrm{pH} 11$ and the minimum removal (55\%) was at $\mathrm{pH} 5$ (Fig. 1(f)). The increasing trend of removal of color with increasing $\mathrm{pH}$ is dependent on the nature of the adsorbent. Date seeds PAC was activated using $\mathrm{ZnCl}_{2}$. $\mathrm{pH}$ of date seeds PAC paste was measured as 4.47 which denotes that the activated carbon is acidic in nature and will have a tendency to react better with aqueous solution of basic nature. This result indicates that removal of contaminants using activated carbon having different surface characteristics (acidic or basic) will have an influence of $\mathrm{pH}$.

\section{Adsorption isotherm}

Batch adsorption studies with different initial concentrations of colored sample were performed in order to determine adsorption isotherms for color removal using date seeds PAC. Isotherm is an emperical relation which is the presentation of the amount of solute (colored particle) adsorbed per unit weight of adsorbent (date seeds PAC). The adsorbent phase concentration after equilibrium is computed using the Eq.(1) as:

$q_{e}=\left(C_{o}-C_{e}\right) V / m$

Where, $q_{e}$ is the amount of solute adsorbed per unit weight of adsorbent $(\mathrm{mg} / \mathrm{g}), C_{o}$ is the initial concentration of adsorbate $(\mathrm{mg} / \mathrm{L}), C_{e}$ is the final equilibrium concentration of solute $(\mathrm{mg} / \mathrm{L}), m$ is the mass of adsorbent $(\mathrm{g})$ and $V$ is the volume of wastewater (Litre).

In this current study, the Freundlich and Langmuir isotherm models were examined. The Freundlich adsorption model illustrated in Eq. (2) is the most widely used mathematical model in aqueous systems. The equation is written as:

$q_{e}=K_{f} C_{e}{ }^{l / n}$

Where, $q_{e}$ is the amount adsorbed at equilibrium $(\mathrm{mg} / \mathrm{g}), C_{e}$ is the equilibrium concentration of adsorbate $(\mathrm{mg} / \mathrm{L}), K_{f}$ is the adsorption capacity constant $(\mathrm{L} / \mathrm{g}), n$ is the intensity constant.
The Freundlich equation is modified in logarithmic form as:

$\log \left(q_{e}\right)=\log \left(K_{f}\right)+1 / n \times \log \left(C_{e}\right)$

The logarithmic form of Freundlich isotherms for color adsorption using date seeds PAC for different temperatures are represented in Fig. 2(a). The isotherm values fitted well with $R^{2}$ value of $0.9967,0.9979$ and 0.9991 for color adsorption under temperatures $30^{\circ} \mathrm{C}, 35^{\circ} \mathrm{C}$ and $45^{\circ} \mathrm{C}$ respectively. The adsorption capacity constant $K_{f}$ and intensity constant $(n)$ at $30^{\circ} \mathrm{C}, 35^{\circ} \mathrm{C}$ and $45^{\circ} \mathrm{C}$ temperature are presented in Table I. Using Freundlich model, the isotherm Eqs. (4), (5) and (6) were obtained for color adsorption at $30^{\circ} \mathrm{C}, 35^{\circ} \mathrm{C}$ and $45^{\circ} \mathrm{C}$ temperature respectively.

$q_{e}=2.80 \times C_{e}^{0.6216}$

$q_{e}=1.57 \times C_{e}^{0.7346}$

$q_{e}=3.85 \times C_{e}^{0.6098}$

The $n$ value indicates the degree of nonlinearity between solution concentration and adsorption as follows: if $n=1$, then adsorption is linear; if $n<1$, then adsorption is a chemical process (chemisorption); if $n>1$, then adsorption is a physical process (physisorption) (Mohan and Karthikeyan, 1997). Here, the values of $n$ obtained from the slopes of the plots were from 1.36 to 1.64 indicating physisorption has taken palce. Specifically, the linear leastsquares method and the linearly transformed equations have been widely applied to correlate sorption data, where $1 / n$ is a heterogeneity parameter. The smaller the $1 / n$, the greater the expected heterogeneity is and values of $n$ between 1 to10 represents favorable adsorption (Mckay et al., 1980, Özer and Pirinççi, 2006).

The Langmuir model was developed based on the assumption of the formation of a monolayer of the adsorbate species onto the surface of the adsorbent and the surface sites are energetically homogeneous. But in the true sense, the adsorbent surface is never energetically homogeneous. The Langmuir adsorption isotherm is interpreted in Eq. (7)as:

$C_{e} / q_{e}=1 /\left(q_{m} \times \mathrm{b}\right)+C_{e} / q_{m}$

Where, $q_{m}$ is monolayer (maximum) adsorption capacity $(\mathrm{mg} / \mathrm{g})$ and $b$ is Langmuir constant related to energy of adsorption (L/mg).

Eq. (7) is used for linearization of the experimental data by plotting $C_{e} / q_{e}$ against $C_{e}$ (Fig. 2(b)). The linearized version fitted well with the observations as $R^{2}$ values of 0.978 , 0.986 and 0.962 were obtained for color removal at temperatures $30^{\circ} \mathrm{C}, 35^{\circ} \mathrm{C}$ and $45^{\circ} \mathrm{C}$ respectively. The values 
(a)

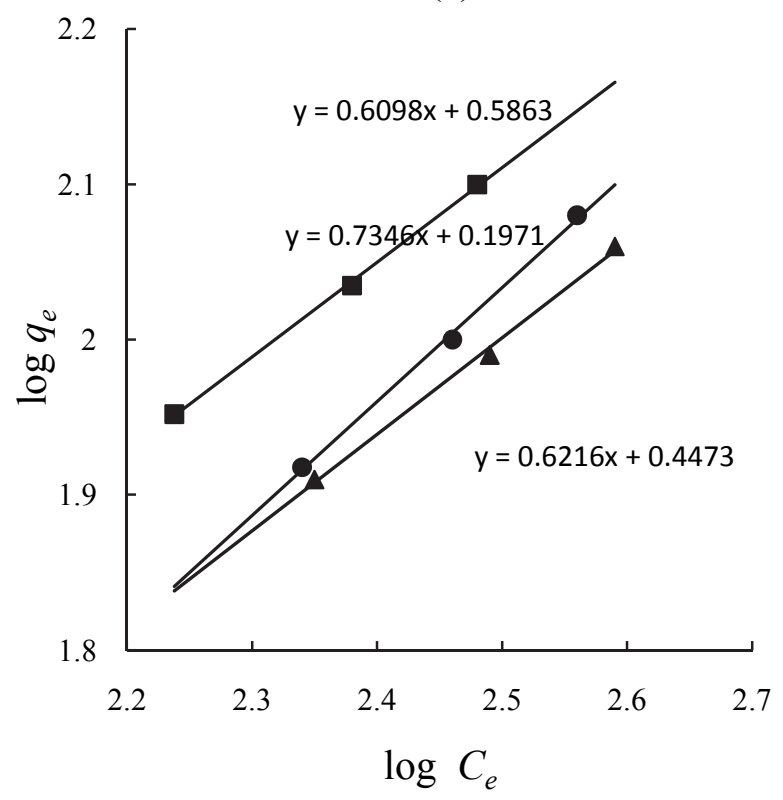

(b)

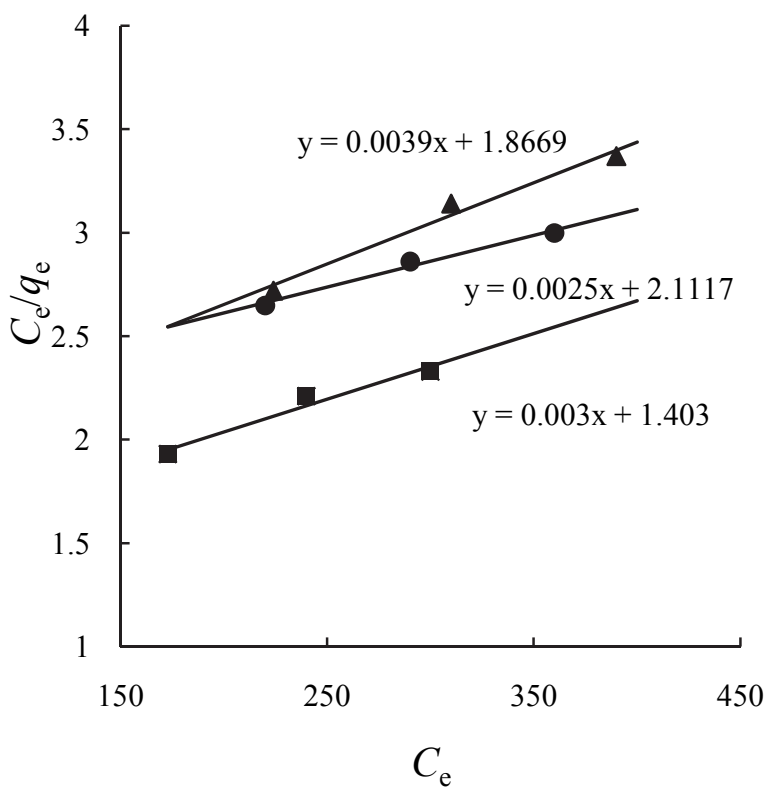

Fig. 2. (a) Freundlich isotherm and (b) Langmuir isotherm for color adsorption. Legends here: (অ) $45^{\circ} \mathrm{C}$ (४) $35^{\circ} \mathrm{C}(\bullet)$ $30^{\circ} \mathrm{C}$ temperature.

$q_{m}$ and $b$ at different temperatures, obtained by fitting Eq. (7) with observed data are presented in Table I. It was estimated that the maximum theoretical adsorption capacity of date seeds $\mathrm{PAC}$ is higher at $35^{\circ} \mathrm{C}$ than at $30^{\circ} \mathrm{C}$ and $45^{\circ} \mathrm{C}$. indicated that the nature of adsorption was favorable. Although isotherm values are represented by both of the linear forms of Freundlich and Langmuir model, the former represents the data slightly better. The other reason for

Table I. Adsorption Isotherm parameters and correlation coefficients $\left(R^{2}\right)$ for color removal using date seeds PAC

\begin{tabular}{lllll}
\hline Adsorption isotherm & \multicolumn{1}{c}{ Isotherm Data } & \multicolumn{1}{c}{$30^{\circ} \mathrm{C}$} & \multicolumn{1}{c}{$35^{\circ} \mathrm{C}$} & $45^{\circ} \mathrm{C}$ \\
\hline & Linear equation & $C_{e} / q_{e}=0.0039 C_{e}+1.8669$ & $C_{e} / q_{e}=0.0025 C_{e}+2.1117$ & $C_{e} / q_{e}=0.0032 C_{e}+11.4034$ \\
Langmuir isotherm & $R^{2}$ & 0.978 & 0.986 & 0.962 \\
& $q_{m}(\mathrm{mg} / \mathrm{g})$ & 256 & 400 & 312 \\
& $b(\mathrm{~L} / \mathrm{mg})$ & 0.0020 & 0.0012 & 0.0017 \\
\hline \multirow{5}{*}{ Freundlich isotherm } & Linear equation & $\log q_{e}=0.4473+0.6216 \log C_{e}$ & $\log q_{e}=0.1971+0.7346 \log C_{e}$ & $\log q_{e}=0.5863+0.6098 \log C_{e}$ \\
& $R^{2}$ & 0.9991 & 0.9979 & 0.9967 \\
& $K_{f}(\mathrm{~L} / \mathrm{g})$ & 2.80 & 1.57 & 3.85 \\
& $n$ & 1.64 & 1.36 & 1.61 \\
\hline
\end{tabular}

The essential features of the Langmuir isotherm can be expressed in terms of dimensionless constant separation factor, $R_{1}$ which is defined by the following relation given by Hall et al., (1966).

$R_{l}=1 /\left(1+b C_{o}\right)$

The nature of adsorption is unfavorable if $R_{l}>1$, linear if $R_{l}=1$ and favorable if $R_{l}<1$. For Date seeds PAC color adsorption, the values of dimensionless separation factor $R_{1}$ obtained using Eq. (8) were within 0.284 - 0.581 which prefering Freundlich model was that its isotherm equation encompasses the heterogeneity of the surface, exponential distribution of sites and their interaction energies. The adsorbent used in this current study (date seeds PAC) is heterogeneous in nature.

\section{Adsorption kinetics}

In this present study three kinetic models were applied for the experimental data with date seeds PAC: the Lagergren pseudo first order kinetic model, the Ho's pseudo second order kinetic model and the intra-particle diffusion model. 
The Pseudo first order kinetic model states that the rate of change of solute uptake with time is directly proportional to difference in saturation concentration and the amount of solid uptake with time (Lagergren, 1898) while the Ho's pseudo second kinetic model is based on the assumption that the adsorption of adsorbate onto adsorbent supports second order chemisorption (Ho and McKay, 1998). The pseudo first order and second order kinetics are expressed through equations (9) and (10) respectively:

$d q_{t} / d t=k_{l}\left(q_{e}-q_{t}\right)$

$d q_{t} / d t=k_{2}\left(q_{e}-q_{t}\right)^{2}$

Where, $q_{t}$ and $q_{e}$ are the amount of adsorbate adsorbed $(\mathrm{mg} / \mathrm{g})$ at contact time $t$ and at equilibrium, $k_{1}$ and $k_{2}$ are the Pseudo first order and 2nd-order rate constants respectively. Solving Eq. (9) and (10) with respect to the initial conditions $\left(t=0, q_{t}=0\right)$ the relationships described in Eq. (11) and (12) can be obtained for pseudo first order and second order kinetic models respectively:

$\log \left(q_{e}-q_{t}\right)=\log q_{e}-\left(k_{l} / 2.303\right) \times t$

$t / q_{t}=1 /\left(k_{2} q_{e}{ }^{2}\right)+t / q_{e}$

The initial adsorption rate $h(\mathrm{mg} / \mathrm{g} / \mathrm{min})$ is also related as (Ho, 2003)

$h=k_{2} q_{e}{ }^{2}$

The plots of $\log \left(q_{e}-q_{t}\right)$ against $t$ for color adsorption for three different initial color concentrations 800, 1000 and 1200 Pt-Co respectively are shown in Fig. 3(a). The plots of $t / q_{t}$ against $t$ for color adsorption for each of the initial

(a)

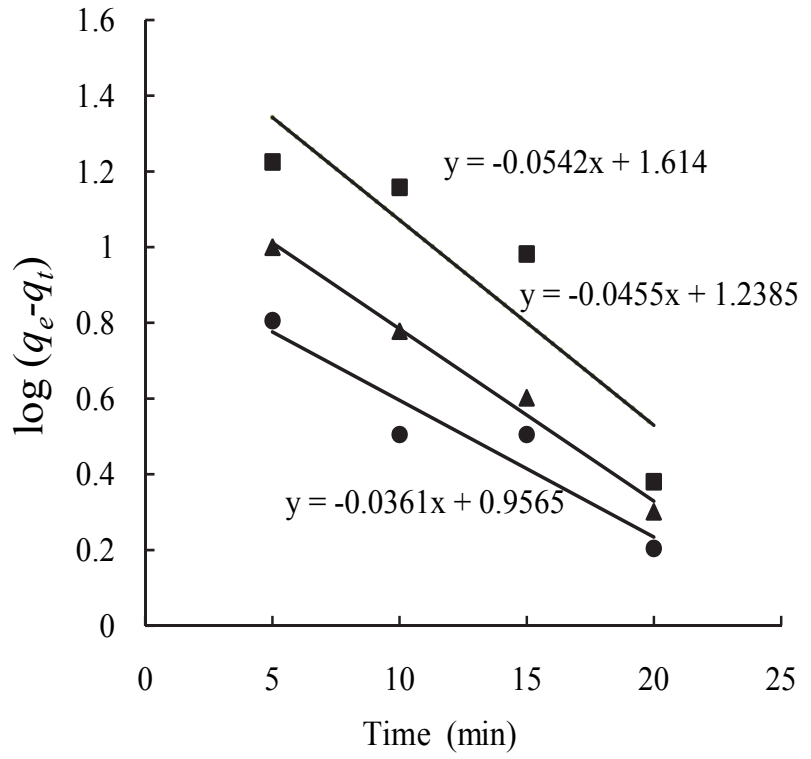

concentrations are shown in Fig. 3(b). A summary comparison of the model parameters is shown in Table II. It can be seen that the second order kinetic model also fitted relatively well $\left(R^{2}=0.99\right)$ for all cases tested over the whole range of contact times for all three different initial concentrations compared to the first order model. Since the pseudo second order kinetic model better represents the experimental data for the adsorption with date seeds PAC, the adsorption process seems to be controlled by chemisorption. Previous adsorption studies also suggests that the pseudo first order kinetic model is generally applicable for the initial stages of adsorption (Ho and Mckay, 1998) and for all ranges of contact times it is less likely to represent the experimental data.

\section{Intra particle diffusion model}

The overall adsorption process may be controlled either by one or more steps, e.g., film or external diffusion, pore diffusion or a combination of more than one step. To understand the exact diffusion mechanism, the experimental data with date seeds PAC were further analyzed with the intra-particle diffusion model (Weber and Morries, 1963). According to Weber and Morris (1963), the amount of adsorbate adsorbed $\left(q_{t}\right)$ is given by the following equation:

$q_{t}=k_{i} t+I$

(b)

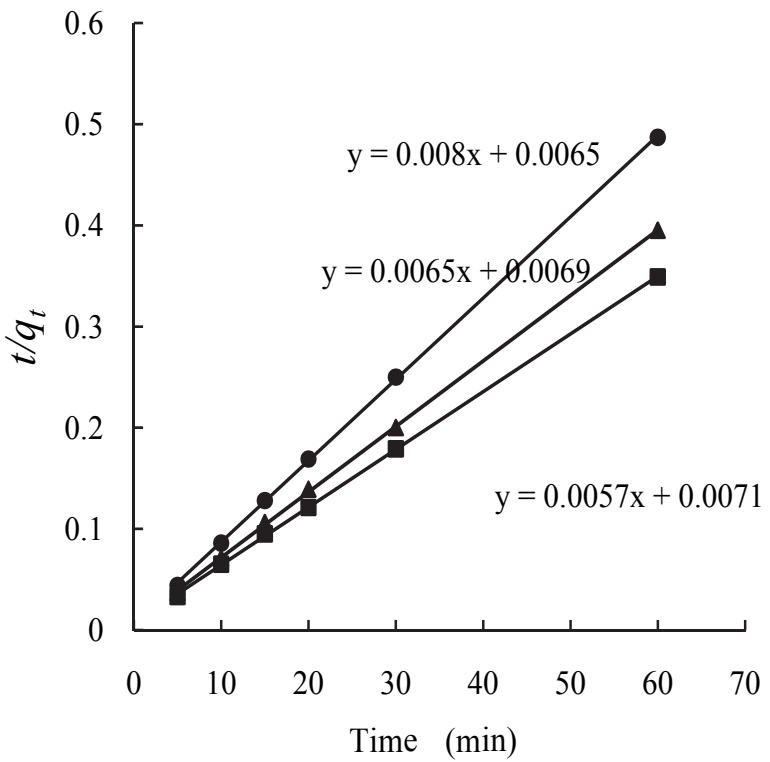

Fig. 3. (a) Pseudo first order, (b) Pseudo second order plot for color adsorption. Legends here: ( $\square$ ) 1200 Pt-Co (A) $1000 \mathrm{Pt}-\mathrm{Co}(\mathrm{O}) \mathbf{8 0 0} \mathrm{Pt}-\mathrm{Co}$ units of initial concentration. 
Table II. Parameters of Pseudo first and second order kinetic model for adsorption with date seeds PAC

\begin{tabular}{ccccccccc}
\hline $\begin{array}{l}\text { Initial Color conc. } \\
\text { (Pt-Co) }\end{array}$ & $q_{e}{ }^{a}$ & \multicolumn{3}{c}{ Pseudo-first order kinetic model } & \multicolumn{4}{c}{ Pseudo-second order kinetic model } \\
\cline { 3 - 10 } & & $k_{1}$ & $q_{e}{ }^{b}$ & $R^{2}$ & $k_{2}$ & $q_{e}{ }^{b}$ & $h$ & $R^{2}$ \\
\hline 800 & 120 & 0.083 & 9.036 & 0.900 & 0.01 & 125 & 129.6 & 0.999 \\
1000 & 146 & 0.104 & 17.3 & 0.988 & 0.006 & 166.67 & 191.8 & 0.999 \\
1200 & 168 & 0.124 & 41.11 & 0.827 & 0.003 & 200 & 169.3 & 0.999 \\
\hline
\end{tabular}

Note: Unit of in Pt-Co (per gram of adsorbent per litre).

${ }^{a}$ Experimental

$\mathrm{b}_{\text {Theoretical }}$

Where, $k_{i}$ is the intra-particle diffusion rate constant, and $I$ is a parameter related to boundary layer thickness. A plot of $q_{t}$ against $t$ (Fig. 4) shows a multi-linear plot indicating a diffusion of color through solution onto the external surface of date seeds PAC. The mildly sloped linear portion (dotted line in Fig. 4) is the gradual adsorption stage with slow

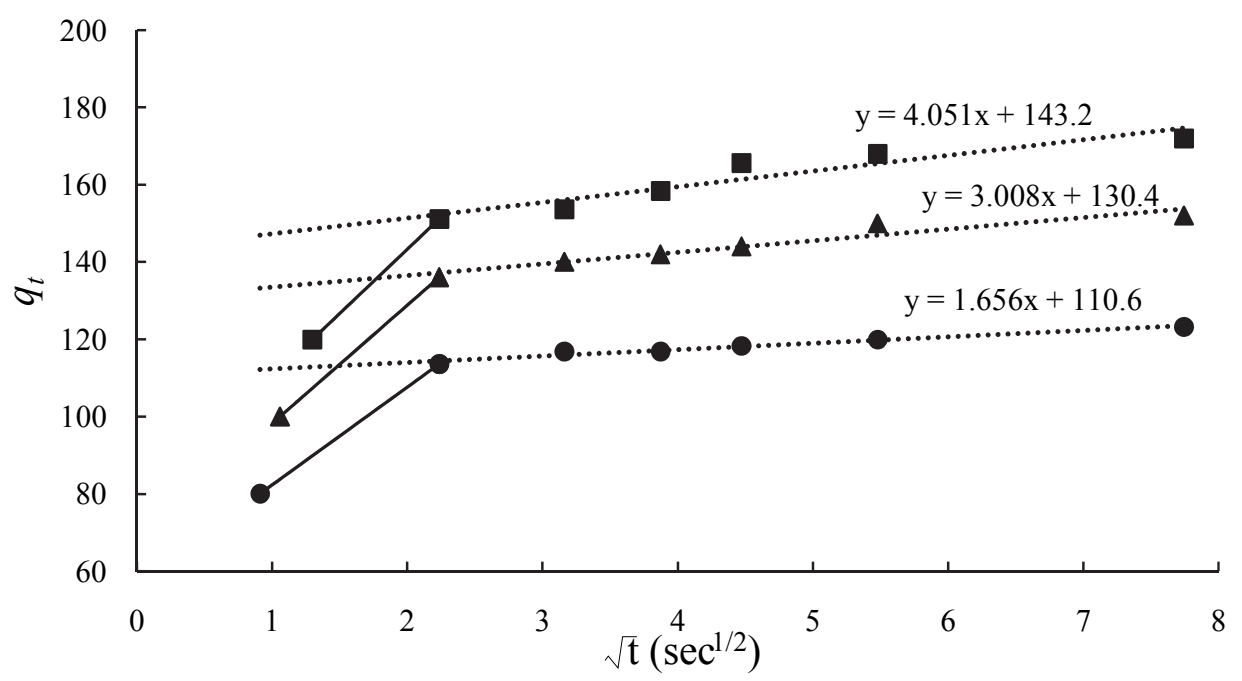

Fig. 4. Intra particle diffusion plot for color adsorption. Legends here: (ם) 1200 Pt-Co (A) 1000 Pt-Co (O) 800 PtCo units of initial concentration. The dotted straight-line represents the best fit intra-particle diffusion model ignoring the initial set of data points when film diffusion dominates.

two-step influence in the sorption process. It is assumed that the external resistance to mass transfer surounding the particles is significant only in the early stages of adsorption; this is represented by initial steeper portion depicting film intra-particle pore diffusion. From the mildly sloped linear portion the values of $k_{i}$ and $I$ were obtained from the slope and intercept respectively and are given in Table III. Typically, the larger the value of $I$, the higher will be the

Table III. Film diffusion and pore diffusion coefficients for color removal using date Seeds PAC

\begin{tabular}{ccccccc}
\hline Initial Color conc. (Pt-Co) & $k_{i}$ & $I$ & $R^{2}$ & $t_{1 / 2}(\mathrm{sec})$ & $D_{p}\left(\mathrm{~cm}^{2} / \mathrm{sec}\right)$ & $D_{f}\left(\mathrm{~cm}^{2} / \mathrm{sec}\right)$ \\
\hline 800 & 1.656 & 110.6 & 0.967 & 49.8 & $3.389 \times 10^{-7}$ & $1.38 \times 10^{-7}$ \\
1000 & 3.008 & 130.4 & 0.924 & 68.4 & $2.467 \times 10^{-8}$ & $1.009 \times 10^{-7}$ \\
1200 & 4.051 & 143.2 & 0.887 & 102 & $1.65 \times 10^{-8}$ & $0.563 \times 10^{-7}$ \\
\hline
\end{tabular}


boundary layer effect. It can be seen that the boundary layer effect (i.e. $I$ value) and $k_{i}$ values increase with the increase in initial color concentration. Assuming spherical geometry of the adsorbents, the overall rate constant of the process can be correlated to the pore and film diffusion coefficient in accordance with the expression (Helfferich, 1962),

$t_{1 / 2}=0.03\left(r_{o}^{2} / D_{p}\right)$

$t_{1 / 2}=0.23 r_{o}\left(\delta / D_{f}\right)\left(C / C_{e}\right)$

Where, $r_{o}$ is radius of the adsorbent $(\mathrm{cm}), D_{f}$ and $D_{p}$ are film and pore diffusion coefficients respectively $\left(\mathrm{cm}^{2} / \mathrm{sec}\right)$, $C / C_{e}$ is equilibrium loading of the adsorbent, $\delta$ is the film thickness $(\mathrm{cm})$ and $t_{1 / 2}$ is the time necessary to obtain half the initial concentration (sec). $t_{1 / 2}$ can be obtained using the following relationship (You et al., 2006):

$t_{1 / 2}=1 /\left(k_{2} q_{e}\right)$

For this study, radius of the adsorbent $\left(r_{o}\right)$ was $0.0075 \mathrm{~cm}$ and the film thickness $(\delta)$ was assumed $0.001 \mathrm{~cm}$ (Helfferich, 1962). Using these values, the film diffusion coefficient $\left(D_{f}\right)$ and pore diffusion coefficient $\left(D_{p}\right)$ were calculated using Equations (15) - (17) (see Table III). Michelson et al., (1975) suggested that if the diffusion coefficient lies between $10^{-6}-10^{-8} \mathrm{~cm}^{2} / \mathrm{sec}$, film diffusion will be rate limiting while if diffusion coefficient is in the range of $10^{-11}-10^{-13} \mathrm{~cm}^{2} / \mathrm{sec}$, pore diffusion will be rate limiting. It was found that estimated film and pore diffusion coefficients were in the range of $0.563 \times 10^{-7}$ $1.38 \times 10^{-7} \mathrm{~cm}^{2} / \mathrm{sec}$ and $1.65 \times 10^{-8}-3.389 \times 10^{-7} \mathrm{~cm}^{2} / \mathrm{sec}$ respectively for initial color concentrations varying between 800 to $1200 \mathrm{Pt}-\mathrm{Co}$ (see Table III). Since the value of coefficient of film and pore diffusion are in the range of $10^{-6}$ to $10^{-8} \mathrm{~cm}^{2} / \mathrm{sec}$ for all three initial concentrations, the film diffusion will be rate limiting and further agitation will increase the rate of adsorption.

\section{Thermodynamics of adsorption}

Thermodynamic parameters provide in-depth information of inherent energetic changes associated with adsorption. Thermodynamic parameters such as change in free energy, $\Delta G(\mathrm{~J} / \mathrm{mole})$, enthalpy, $\Delta H(\mathrm{~J} / \mathrm{mole})$ and entropy, $\Delta S$ $(\mathrm{J} / \mathrm{K} / \mathrm{mole})$ can be determined using following equations:

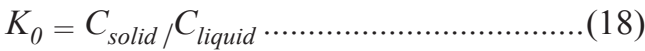

$$
\begin{aligned}
& \Delta G=R T \ln K_{0} \\
& \ln K_{0}=(\Delta S / R)-(\Delta H / R T)
\end{aligned}
$$

Where, $K_{0}$ is equilibrium constant, $C_{\text {solid }}$ is solid phase concentration at equilibrium $(\mathrm{mg} / \mathrm{L}), C_{\text {liquid }}$ is liquid phase concentration at equilibrium $(\mathrm{mg} / \mathrm{L}), T$ is absolute temperature $(\mathrm{K}), R$ is gas constant $(R=8.314 \mathrm{~J} / \mathrm{K} / \mathrm{mole})$. $K_{0}$ is the ratio of the concentration of adsorbate in adsorbent and concentration of adsorbate in aqueous solution at equilibrium.

$\Delta G$ values obtained from Eq. (19) are presented in Table IV. According to Eq. (20), a plot of $\ln K_{0}$ against $1 / t$ for different initial concentrations will have a linear relationship (Fig. 5). $\Delta H$ and $\Delta S$ values were obtained from the slope and intercept respectively of the best-fit straight-line (see Table IV). The negative value of $\Delta G$ indicates that the adsorption is favorable and spontaneous. The absolute value of $\Delta G$ decreases with increase in temperature which indicates that adsorption with date seeds PAC is an endothermic process. The positive values of $\Delta H$ indicate that the removal of color onto date seeds PAC is endothermic in nature, which is supported by the fact that increase in removal of color by date seeds PAC is associated with the increase in temperature. This may be attributed to increased surface coverage at higher temperature, expansion and creation of reactive and active sites. The low values of $\Delta H(0.26$ to $0.28 \mathrm{~kJ} / \mathrm{mole})$ indicate that physical adsorption may be the dominant mechanism.

\begin{tabular}{|c|c|c|c|c|c|c|c|c|}
\hline \multirow{2}{*}{$\begin{array}{l}\text { Initial Color conc. } \\
\quad(\mathrm{Pt}-\mathrm{Co})\end{array}$} & \multicolumn{3}{|c|}{$K_{0}$} & \multicolumn{3}{|c|}{$\Delta G(\mathrm{~kJ} / \mathrm{mole})$} & \multirow{2}{*}{$\underset{(\mathrm{kJ} / \mathrm{mole})}{\Delta H}$} & \multirow{2}{*}{$\underset{(\mathrm{J} / \mathrm{K} / \text { mole })}{\Delta S}$} \\
\hline & $303 \mathrm{~K}$ & $308 \mathrm{~K}$ & $318 \mathrm{~K}$ & $303 \mathrm{~K}$ & $308 \mathrm{~K}$ & $318 \mathrm{~K}$ & & \\
\hline 800 & 2.57 & 2.63 & 3.62 & -2.37 & -2.47 & -3.40 & 0.27 & 1.01 \\
\hline 1000 & 2.22 & 2.45 & 3.16 & -2.00 & -2.29 & -3.04 & 0.26 & 0.97 \\
\hline 1200 & 2.07 & 2.33 & 3.00 & -1.83 & -2.16 & -2.90 & 0.28 & 1.01 \\
\hline
\end{tabular}

Table IV. Thermodynamic parameters for color adsorption 
(Arivoli, 2007 and Renmin et al., 2005). This may be in contrast to the findings of the previous section where the data seem to follow the second order kinetic model indicating chemisorption to be the governing process in adsorption. However we think that both physisorption and chemisorption could be controlling adsorption at various degrees and a clear demarcation as to which one is governing cannot be made. The positive values of $\Delta S$ indicate increased disorder and randomness at the solid solution interface of adsorbate with the adsorbent. This is the normal consequence of the physical adsorption phenomenon, which takes place through electrostatic interactions (Fat'hi et. al., 2014). The increase of adsorption capacity of the adsorbent at higher temperatures was probably due to enlargement of pore size and activation of adsorbent surface (Weber, 1967 and Vadivelan and Vasanthkumar, 2005).

\section{Conclusion}

The PAC from date seeds, as a low cost adsorbent, has been found to be efficient for the removal of color of textile effluent as a high percentage of color removal was obtained for a wide range of initial color concentrations from batch experiments. In characterizing the adsorption process, it was found that both Freundlich and Langmuir isotherms represent the adsorption process with date seeds PAC reasonably well while the Freundlich isotherm representing the data slightly better than the other. Pseudo second order kinetic model fitted well with whole range of contact time indicating that the adsorption process is controlled by chemisorption. Both external film and intraparticle pore diffusion mechanism were involved in the adsorption of color onto date seeds PAC over the range of contact times tested but film-diffusion has been found to be rate-limiting in this case. The removal of color onto date seeds PAC has been found to be endothermic in nature and increased color removal was associated with the increase in temperature. Being abundant and a lowcost agricultural byproduct in Bangladesh and at the same time being an efficient adsorbent, date seeds have good prospects for being utilized for tertiary treatment of textile wastewater in Bangladesh as a polishing step before discharging into the receiving water bodies and thereby safeguarding the environment against the detrimental effects of colored wastewater.

\section{Acknowledgement}

Author would like to express his gratitude to Committee for Advanced Studies and Research (CASR), BUET for financial support to carry out this research work. Special thanks to the staff of Environmental Engineering Laboratory of BUET for their assistance in carrying out the experiments. Also special thanks to Echo Tex. Pvt. Ltd. for providing wastewater samples.

\section{References}

Abdus-Salam N and Buhari M (2014), Adsorption of Alizarin and Fluorescein Dyes on Adsorbent prepared from Mango Seed, The Pacific Journal of Science and Technology 15(1): 232-244.

Al-Ghouti M, Khraisheh MA, Ahmad MN and Allen S (2005), Thermodynamic behavior and the effect of temperature on the removal of dyes from aqueous solution using modified diatomite: a kinetic study, $J$ Colloid Interface Sci. 287(1): 6-13.

Alqaragully MB (2014), Removal of textile dyes (maxilon blue, and methyl orange by date stones activated carbon, International Journal of Advanced Research in Chemical Science 1(1): 48-59.

Arivoli S. (2007), Kinetic and thermodynamic studies on the adsorption of some metal ions and dyes onto low cost activated carbons Ph.D Thesis, Gandhigram Rural University, Gandhigram, India.

Churchley JH (1994), Removal of dye wastewater color from sewage effluent- the use of full-scale ozone plant, Water Sci Technol. 30(3): 275.

El-Nemr A, El-Sikaily A, Abdelwahab O and Khaled A (2009), Direct dye (DB-86) removal from aqueous solution by adsorption using activated carbon from orange peel, J of Hazard Mater. 161: 102-110.

Fat'hi MR, Asfaram A, Hadipour A and Roosta M (2014), Kinetics and thermodynamic studies for removal of acid blue 129 from aqueous solution by almond shell, J Environ Health Sci Eng. 12(1): 62.

Geçgel Ü, Özcan G and Gürp nar GÇ (2013), Removal of Methylene Blue from Aqueous Solution by Activated Carbon Prepared from Pea Shells (Pisumsativum), Journal of Chemistry, Volume 2013, Article ID 614083.

Guendy HR (2006), Removal of dyestuffs from wastewater by activated carbon, Egypt $J$ of Aquat Res. 32(Special Issue): 146-159.

Habib A, Hasan Z, Rahman ASMS and Alam AMS (2006), Tuberose sticks as an adsorbent in the removal of Methylene Blue from aqueous solution, Pakistan J Anal and Environ Chem. 7(2): 112-115. 
Hall KR, Eagleton LC, Acrivos A and Vermeulen T (1966), Pore and solid diffusion kinetics in fixed bed adsorption under constant pattern condition, Ind Eng Chem Fundamental 5: 212-223.

Helfferich FG (1962), Ion Exchange, McGraw Hill, New York 1962, pp 72-94.

Ho YS and Mckay G (1998), The kinetics of sorption of basic dyes from aqueous solution by sphagnum moss peat, Can J Chem Eng. 76: 882-827.

Igwegbe CA, Onyechi PC, Onukwuli OD and Nwokedi IC (2016), Adsorptive treatment of textile wastewater using activated carbon from mucunapruriens seed shells, World Journal of Engineering and Technology 4: 21-37

Islam MA, Tan LAW, Benhouria A, Asif M and Hameed BH (2015), Mesoporous and adsorptive properties of palm date seed activated carbon prepared via sequential hydrothermal carbonization and sodium hydroxide activation, Chem Eng J. 270: 187-195.

Kadirvel K, Kavipriya M, Karthika C, Radhika M, Vennilamani W and Pattabhi S (2003), Utilization of various agricultural wastes for activated carbon preparation and application for the removal of dyes and metal ions from aqueous solution, Bioresour Technol. 87: 129-132.

Karim MM, Das AK and Lee SH (2006), Treatment of colored effluent of the textile industry in Bangladesh using zinc chloride treated indigenous activated carbons, Anal Chim Acta. 576: 37

Khehra MS, Saini HS, Sharma DK, Chadha BS and Chimni SS (2005), Decolorization of various azo dyes by bacterial consortium, Dyes and Pigments, 67: 55-61.

Lagergren S (1898), Zur theorie der sogenannten adsorption geloster stoffe, Kungliga Svenska Vetenskapsakademiens, Handlingar. 24(4): 1- 39.

Malik PK (2003), Use of activated carbon prepared from sawdust and rice husk for adsorption of acid dyes: A case study of yellow 36, Dyes and Pigments, 56: 239249 .

McKay G, Otterburn MS, and Sweeney AG (1980), The removal of colour from effluent using various adsorbents III Silica: rate processes, Water Res. 14(1): 15-20.
Michelson LD, Gideon PG, Pace EG and Kutal LH (1975), Removal of soluble mercury form wastewater by complexing techniques, US Dep Ind Water Res and Technol. Bull No: 74.

ECR (1997), Bangladesh Environment Conservation Rules 1997, Department of Environment, Ministry of Environment and Forests, Government of the People's Republic of Bangladesh.

Mohan S, and Karthikeyan J (1997), Removal of lignin and tannin color from aqueous solution by adsorption on to activated carbon solution by adsorption on to activated charcoal, Environ Pollut. 97: 183-187.

Namasivayam C (1995), Adsorption for the treatment of wastewaters. In: Encyclopedia of Environmental Pollution and Control, vol. 1, Ed. Trivedy RK, Enviro-medial, Karad, Maharastra, India pp 30-49.

Nigarn P, Banat CM, Sigh D and Marchant R (1996), Microbial process for decolorisation of textile effluents containing azo, diazo and reactive dyes, Process Biochem. 3: 435-442.

Özer A, and Pirinççi HB (2006), The adsorption of Cd (II) ions on sulphuric acid-treated wheat bran, $J$ of Hazard Mater. 137(2): 849-855.

Pollard SJT, Fowler GD and Sollars CJ (1992), Adsorption for the treatment of wastewaters, The Sci of the Total Environ. 116: 33-52.

Quader AKMA (2010), Wastewater treatment in textile industries for clean environment. Department of Chemical Engineering, BUET, Dhaka, Bangladesh.

Rahman M, Bari QH, Mohammad N, Ahsan A, Sobuz HR, and Uddin MA (2013), Characterization of rice husk carbon produced through simple technology, Advances in Mater Sci and Application 2(1): 25-30.

Reddy KSK, Shoaibi AA and Srinivasakannan C (2012), Activated Carbon from date Palm Seed: Process Optimization Using Response Surface Methodology, Waste Biomass Valorization 3: 149-156.

Renmin G, Yingzhi S, Jian C, Huijun L and Chao Y (2005), Effect of chemical modification on dye adsorption capacity of peanut hull, Dyes and Pigments 67: 175-181. 
Vadivelan V and Vasanthkumar K (2005), Equilibrium, kinetics, mechanism, and process design for the sorption of methylene blue onto rice husk, $J$ Colloid Interface Sci. 286(1): 90-100.

Weber WJ (1967), Principle and application of water chemistry, Eds Faust SD and Hunter JV, New York: Wiily.

Weber WJ and Morris CJ (1963), Kinetics of adsorption on carbon from solution, J Sanit Eng Division, 89: 31-60.
Yeh RYL, Hung YT, Liu RLH, Chiu HM and Thomas A (2002), Textile wastewater treatment with activated sludge and powdered activated carbon, International journal of environmental studies 59(5): 607-622

You L, Wu Z, Kim T and Lee K (2006), Kinetics and thermodynamics of bromophenol blue adsorption by a mesoporous hybrid gel derived from tetraethoxysilane and bis (trimethosysilyl) hexane, J Colloid Interface Sci. 300: 526-535.

Received: 04 April 2016; Revised: 14 June 2016; Accepted: 28 July 2016. 